\title{
Legacy of the doctors' strike and the Saskatoon Agreement
}

$\Delta$ clear consensus exists today in Canada, that we need major health system reform to improve quality, safety and value for money. However, we remain polarized on one critical issue: Is the way in which the practice of medicine in Canada is governed and remunerated a structural impediment to major health system reform aimed at improving lagging performance? There are two conflicting responses.

In their reports delivered to the governments of Ontario and Canada, respectively, in recent months, the Price and Naylor committees concluded that governance and payment for physicians need a major overhaul. Doctors must become accountable to the health systems and the patients they serve, with forms of payment that will remunerate them to provide higherquality and more timely services and that will hold them more directly answerable to health system organizations for their performance. ${ }^{1,2}$

In contrast, provincial medical associations still defend the current status of doctors as independent contractors, not directly accountable to the health care organizations and regional health authorities within which they work, along with the fee-for-service model of remuneration. Some individuals go further, attacking the principles and regulations underpinning medicare. Vancouver physician and former president of the Canadian Medical Association Dr. Brian Day has launched a lawsuit against provincial restrictions on dual "public-private" practice and private health insurance for medicare services. In his view, these rules prevent the provision of timely, high-quality medical care and breach fundamental individual rights as protected under the constitution. ${ }^{3}$ Dr. Noel Doig, a Saskatchewan family physician and anti-medicare activist in the 1960s, recently argued

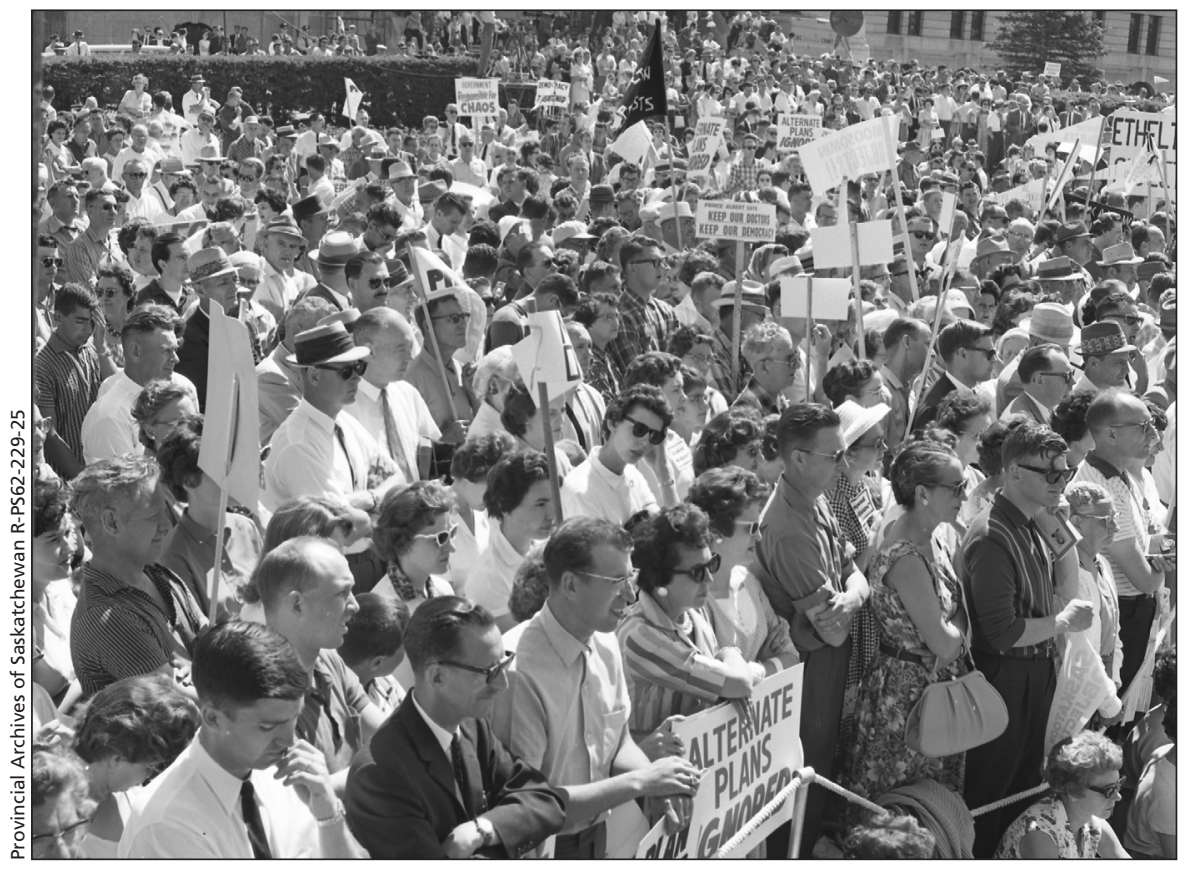

Figure 1: On July 11, 1962, in the midst of the province-wide doctors' strike (July 1-23), an anti-medicare demonstration, attracting about 4000 people, was held in front of the Saskatchewan legislature, in an effort to get the province's CCF (Co-operative Commonwealth Federation) government to halt implementation of universal coverage for medical care.

that medicare itself is responsible for the poor quality of Canadian health care and that we need to return to a premedicare status quo, where patients pay physicians directly to ensure patientphysician accountability. ${ }^{4}$

To understand the context of this debate, we need to go back to the very beginning, to 1962 , when universal medical care coverage was first introduced in Saskatchewan, on the heels of a bitter 23-day doctors' strike that divided the population and attracted worldwide attention (Figure 1). The strike produced a stalemate between the provincial government and the doctors, which was only resolved through a negotiated compromise known as the Saskatoon Agreement. ${ }^{5}$

At the time, the quid pro quo seemed simple. In response to concerns about clinical and professional autonomy, the provincial government allowed doctors to extra-bill or even opt out of medicare and to make fee-for-service payment the dominant form of remuneration. Administering a billing system based exclusively on fee-for-service physician practice, the Saskatchewan government would end up choking off the growth of community clinics that included other health care providers in interprofessional group practices.

Following the same administrative model when setting up their own medicare schemes in the late 1960s and early 1970s in response to federal cost-sharing, other provincial governments joined Saskatchewan in giving physicians a virtual monopoly to provide all medical care services, a privileged position that organized medicine has, understandably, been reluctant to give up.

Seen as a difficult compromise for both sides at the time, there were some anti-medicare as well as pro-medicare 
activists who seriously questioned the arrangement in the 1960s. By the 1970s, the questions had faded, and the terms of the deal had become part of the working assumptions of the Canadian system - with one exception. Physician extra-billing intensified to the point that it became a serious impediment to patient access in some provinces. On the basis of Justice Emmett Hall's report to the federal minister of health, ${ }^{6}$ the federal government finally took action and passed the Canada Health Act, which officially discouraged extra-billing and user fees. By threatening reductions in its cash transfers to the provinces, the federal government convinced provincial governments to halt extra-billing, and the practice faded by 1987.7

In the 1990s, most provincial governments introduced regional health authorities, to begin managing health services with a view to better coordination and integration across the continuum of care, and thus to improve quality and efficiency. However, doctors were not held accountable to the new organizations. Instead, they continued to be paid directly by provincial ministries of health, mainly on a fee-for-service basis, a direct result of no government being willing to upset the apple cart of the Saskatoon Agreement.

By the turn of the 21st century, Canadians had made their dissatisfaction with the quality of care and timeliness of delivery well known. Federal and provincial governments commissioned reports to find out what was wrong. In 2002, the Romanow Commission recommended major changes to physician accountability and remuneration as part of a national health reform agenda. ${ }^{8}$

On the ground, however, hardly any provincial government was willing to take on the sacred cow of the Saskatoon Agreement. The one exception was Ontario, where the government, working with the Ontario Medical Association, created a "coalition of the willing" in primary care. In return for higher remuneration, physicians entered group practices based on salary or capitation - a payment based on the size of the enrolled patient population - supplemented by (or "blended" with) other forms of remuneration, including some fee-for-service. Doctors who preferred fee-for-service as their main form of income could still get higher pay by joining group practices built on the traditional fee-for-service model. In all of the new primary care models, however, governance and accountability remained the same: primary care doctors continued to operate as independent contractors with no direct health system accountability.

This same accountability applies to specialists in Canada. They do not work for the hospitals and health regions in which they practice. Instead, they remain independent contractors accountable to their own regulatory bodies but not to the organizations responsible for providing their services to patients.

In his history of the National Health Service (NHS), Rudolf Klein referred to a similar social compact in the United Kingdom. The British government considered the "secret garden of professional autonomy" sacrosanct until budget cutting and internal market reforms under Margaret Thatcher marked a reorientation of the NHS from "producer to consumer values" in the 1980 s. ${ }^{9}$ Of course, professional autonomy could only mean physician autonomy in the context of the NHS, given the status of nonphysician clinicians (e.g., nurses) as salaried employees of the NHS.

Despite their ideological differences, subsequent Conservative and Labour governments in the UK have continued to put users ahead of producers in their ongoing reforms of the NHS. Although this has made life difficult for both clinicians and managers, performance has improved steadily, to the point that, according to the most recent Commonwealth Fund international survey, ${ }^{10}$ the UK has consistently outperformed 10 other countries within the Organisation for Economic Co-operation and Development on a group of common quality, access, efficiency and equity indicators. As we are now so painfully aware, Canada scored near or at the bottom on these same indicators, a result that added considerable fuel to the already burning concerns about the state of health care delivery in Canada. ${ }^{10}$

We will have to enter the secret garden of physician autonomy as part of health reform in Canada. As the founding bargain, the terms of the Saskatoon Agreement have been difficult to change. This bargain may have given Canada great stability in terms of its health system but at the price of making health reform far more difficult than in other comparable countries, such as the UK.

\section{Gregory P. Marchildon PhD}

Professor and Ontario Research Chair in Health Policy and System Design, Institute of Health Policy, Management and Evaluation, University of Toronto, Toronto, Ont.

\section{References}

1. Price D, Baker E, Golden B, et al. Patient care groups: a new model of population based primary health care for Ontario. Toronto: Primary Health Care Expert Advisory Committee; 2015.

2. Naylor D, Girard F, Mintz J, et al. Unleashing innovation: excellent healthcare for Canada. Report of the Advisory Panel on Healthcare Innovation. Ottawa: Health Canada; 2015. Available: www. healthycanadians.gc.ca/publications/health-system -systeme-sante/report-healthcare-innovation-rapport -soins/alt/report-healthcare-innovation-rapport-soins -eng.pdf (accessed 2015 Nov. 2)

3. Peden A. Backgrounder: court challenges to one-tier medicare. Winnipeg: EvidenceNetwork.ca; 2014 Oct. 15. Available: http://umanitoba.ca/outreach/ evidencenetwork/archives/20743 (accessed 2015 Nov. 2).

4. Doig N. Setting the record straight: a doctor's memoir of the 1962 medicare crisis. Saskatoon: Indie Publishing; 2012.

5. Badgley RF, Wolfe S. Doctors' strike: medical care and conflict in Saskatchewan. New York: Atherton Press; 1967.

6. Hall EM. Royal Commission on Health Services. Vol. 1. Ottawa: Queen's Printer; 1964.

7. Taylor MG. Health insurance and Canadian public policy: the seven decisions that created the Canadian health insurance system and their outcomes. 2nd ed. Montréal: McGill-Queen's University Press; 1987:462.

8. Romanow RJ. Building on values: the future of health care in Canada. Saskatoon: Commission on the Future of Health Care in Canada; 2002.

9. Klein R. The new politics of the NHS: from creation to reinvention. Oxford: Radcliffe Publishing; 2006:121.

10. Davis K, Stremikis K, Squires D, et al. Mirror, mirror on the wall: how the performance of the U.S. health care system compares internationally - 2014 update. New York: Commonwealth Fund; 2014 Available: www.commonwealthfund.org/ /media/ files/publications/fund-report/2014/jun/1755_davis_ mirror_mirror_2014.pdf (accessed 2015 Nov. 2).

This article has been peer reviewed.

CMAJ 2016. DOI:10.1503/cmaj.151360 